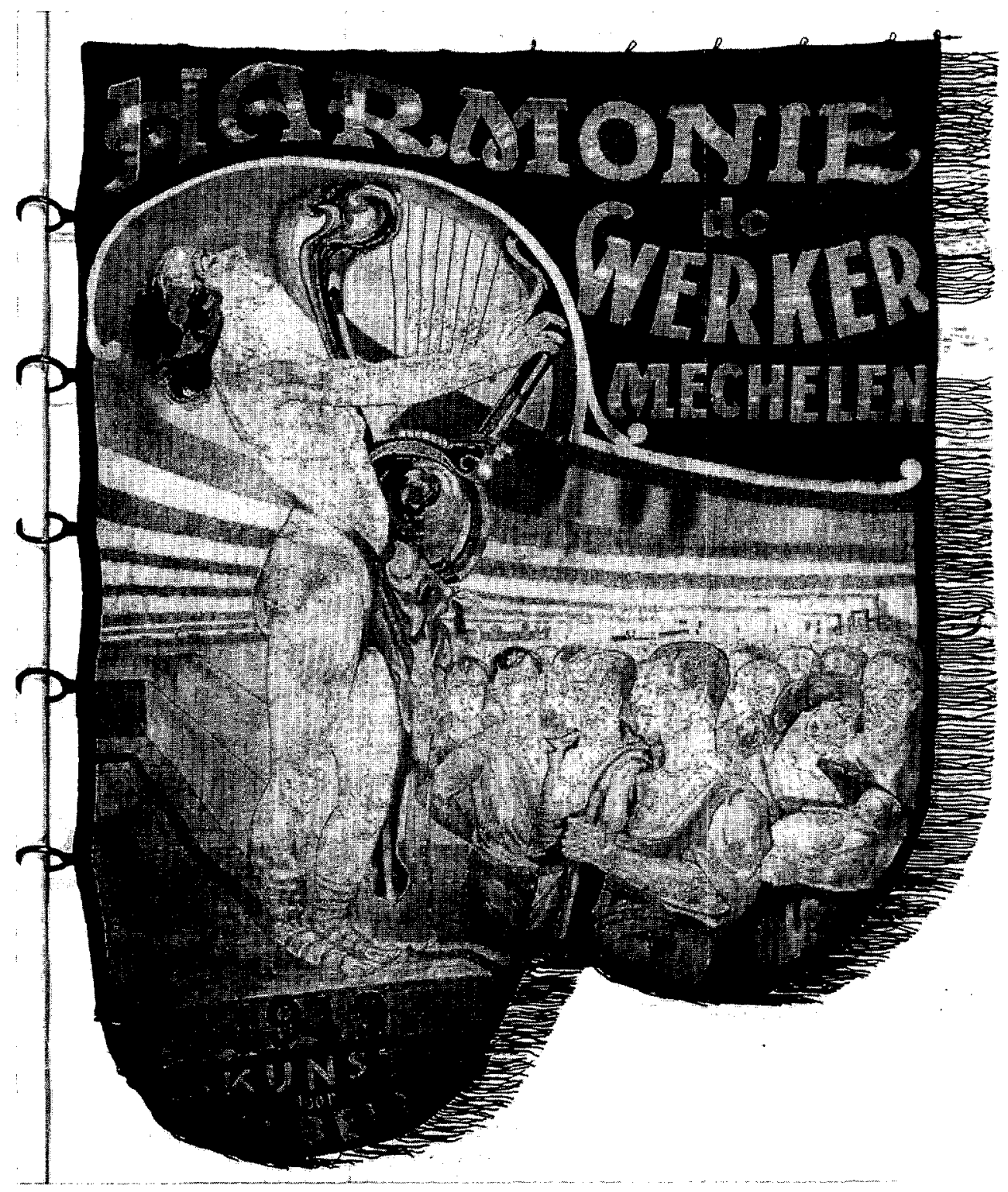

De geweven vlag van Harmonie De Werker van Mechelen 


\section{Gevaarlijke vlag in Mechelen}

Brigitte De Mulder, departement Beeld en Geluid AMSAB

Van bij haar ontstaan was de arbeidersbeweging op zoek naar een eigen beeldentaal. Hiervoor putte zij symbolen en voorstellingen uit de myrhologie, de klassieke oudheid en de christelijke wereld. Zij wilde geen intellectuele benadering of een hoog abstractieniveau; veeleer zocht zij naar een populaire beeldvorming die zo dicht mogelijk de belevingswereld van de doelgroep benaderde. De beelden die gebruikt werden hadden een lage drempel, en door hun eenvoud kon men in één blik de aard en de bedoeling van de organisatie begrijpen.

Tussen 1850 en 1860 duiken de eerste vroegsocialistische arbeidersverenigingen op. Om het wettelijk verbod op samenspanning te omzeilen, de wet Le Chapelier, namen deze organisaties de vorm aan van mutualiteiten en coöperaties. Reeds voóór deze oudste verenigingen was het bezitten van een vaandel een prioriteit en symbool van actieve participatie aan het openbaar leven. Een vlag of vaandel stelde de strijd voor voor een rechtvaardiger en beter leven. Bovendien was de vereniging door haar vlag herkenbaar en werd deze al snel een pronkstuk, een statussymbool waarmee ze zoveel mogelijk indruk wilde maken.

Er zijn natuurlijk de beperkingen van het medium. Het materiaal, zijde of fluweel, en het feit dat deze vlaggen weer en wind moesten kunnen trotseren, maakten dat zowel vlaggenontwerpers als borduurateliers zich aan welbe- paalde regels moesten houden. Alleen heel algemene en heel duidelijke symbolen werden gebruikt, omdat ze vanop afstand zichtbaar en herkenbaar moesten zijn. Ondanks deze praktische begrenzingen blijven het pareltjes, dankbare studieobjecten van de socialistische iconografie.

Een mooi voorbeeld hiervan is de vlag van Harmonie De Werker van Mechelen. Gezien de techniek en de materiaalkeuze - geweven tapijt - vormt ze een uitzondering in de AMSABvlaggencollectie die voornamelijk bestaat uit zijden en fluwelen vlaggen en vaandels.

Reeds sinds de tweede helft van de $19 \mathrm{e}$ eeuw, toen de arbeidersbeweging zich begon te organiseren, was men ervan overtuigd dat materiële en culturele ontvoogding hand in hand moesten gaan. Talloze verenigingen werden hiertoe opgericht en waren actief op filosofisch, sociaal en cultureel vlak. De uitbouw van het sociaal-cultureel net kende vooral tijdens de tussenoorlogse periode een ware explosie. De turnkringen, voetbalploegen, fanfares, biljartclubs, duivenbonden, fietsclubs, toneelkringen, bibliotheken, toeristenbonden, fotoclubs en jeugdgroepen waren toen nauwelijks nog te tellen. Tot deze bonte groep behoorde Harmonie De Werker.

Een archief van de Harmonie van Mechelen is ons niet bekend. Het banier vermeldt het jaartal 1919, stichtingsjaar van de muziekvereniging; de eerste leider ervan was Jan Van Steenwegen. De Mechelse socialistische arbeidersbeweging had toen reeds een lange en bewogen periode achter de rug. Het was namelijk in Mechelen, kerkelijke hoofdstad van België, dat de Vlaamse Socialistische Partij werd opgericht tijdens het congres van 20 en 21 mei 1877. In augustus 1886 plande de BWP-afdeling Mechelen haar vlaginhuldiging. De burgemeester vreesde blijkbaar het ergste want hij schreef 


\section{POLICIFVERORDPUIIG aangaando do rolleloozo on rerolutiomaire manifostalies:}

De Gemeenteraad der stad Mechelen,

Overwegende dat, in de tegenwoordige omstandigheden, het vertoonen der roode vaan en andere kenteekenen van den zelfden aard eene oorzaak van wanordelijkheden kan zijn, welke het van belang is te voorkomen;

Gezien de wet van 16-24 Augusti 1790 en de artikels 78 en 94 der gemeentewet van 30 Maart 1836.

BESLUIT:

Art. 1. - Zijn verboden : alle vertooning van roode vaan en van alle andere voorwdrpen. een wettelnos of revolutionnair kenmerk hebbende, alsook alle samenloopen en optochten met vertooning van dergelijke voorwerpen, of vergezeld van zangen, geroep, muziek, gerucht of onverschillig welke manifestaties, bovengemeld kenmerk aanremende.

Art. 2. - Iedere overtreding der voorgaande bepalingen zal gestraft worden met eene boete van 15 tot 25 fr. en eene gevangenzetting $\operatorname{van} 3$ tot 7 dagen.

Er zal een afschrift van het tegenwoordig besluit aan de bestendige Deputatio van den provincialen Raad overgezonden worden.

zie cat: 17

Als reactie op de vraag van SJW-Mechelen om zijn vlag te mogen inhuldigen, vaardigde het Mechelse stadsbestuut deze politieverordening uit 
onmiddellijk een brief naar generaal Pontus, toenmalig minister van Oorlog, met de vraag om extra soldaten te sturen om het Mechelse garnizoen te versterken!

In december van datzelfde jaar schreef de Socialistische Jonge Wacht van Mechelen een brief - in rode inkt - aan het stadsbestuur, met de vraag om zijn vlag.te mogen inhuldigen. De reactie van de Mechelse overheid was niet mis te verstaan, want onmiddellijk vaardigde zij een 'politieverordening aangaande wettelooze en revolutionnaire manifestaties' uit. De rode vaan werd erin omschreven als de oorzaak van wanordelijkheid. Dit gold eveneens voor het spelen van muziek in de optochten. Overtreders moesten zich aan een boete tussen 15 en 25 fr verwachten én aan een gevangenisstraf van drie tot zeven dagen.

Een nieuw verbod dook op in 1892, toen de socialisten in Mechelen een optocht wilden houden op 15 januari 1892. De optocht mocht niet vergezeld zijn van muziek, zang, vlaggen, opschriften of andere zinnebeelden.

En het stadsbestuur volhardde in deze boosheid in een schrijven van 30 april 1895, gericht aan de provinciegouverneur om te melden dat elke stoet en meeting op 1 mei 1895 verboden werden. Wanneer dan in 1902 socialisten en liberalen samen een betoging wilden organiseren voor het algemeen stemrecht, werd de toestemming hiervoor opnieuw botweg geweigerd! Deze moeilijkheden illustreren duidelijk de angst van Kerk en kapitaal voor het 'rode gevaar'. Toch was dit geen alleenstaand geval; zowat in heel Vlaanderen waren, rond de eeuwwisseling, dergelijke verboden schering en inslag.

Naar alle waarschijnlijkheid zijn deze problemen Harmonie De Werker bespaard gebleven. Het banier werd ingehuldigd op zondag 25 september 1921, samen met de vlag van de $\mathrm{Me}$ - taalbewerkers, de Zang- en Toneelkring Gelijkheid en recht, de Vrouwenvereniging en De roode Turners. Bovendien werden de nieuwe lokalen van de Ziekenbond De Voorzorg ingehuldigd en het vijfendertigjarig bestaan van de Metaalbewerkersvakbond gevierd.

In de zeer schaarse correspondentie die we vandaag nog bezitten, vinden we onder meer de uitnodiging voor een 'crochetavond' op 24 januari 1940. Harmonie De Werker zou dan populaire muziek spelen, als ontspanning voor alle soldaten gelegen in het Mechelse kanton. Het concert zou plaatsvinden in zaal Alcazar op de Botermarkt.

Het banier zou geweven zijn bij de tapijtenfirma Gaspard De Wit. Na contact met de nog steeds bestaande Koninklijke Manufaktuur van Wandtapijten Gaspard De Wit kon dit noch bevestigd noch ontkend worden. Dit geld took voor het ornament in smeedwerk dat bij het banier hoort. Dit zou gemaakt zijn bij de firma Verheylen, maar ook deze informatie kon niet geverifieerd worden. 